\title{
Semantic and Cognitive Structure of Emotion States Love, Lust, Infatuation, Passion
}

\author{
Nataliya Lavrova \\ Moscow State Pedagogical University \\ Correspondence concerning this article should be addressed to Nataliya Lavrova, Moscow State \\ Pedagogical University, Russia, 88 prospekt Vernadskogo, Moscow, Russia, 119571. \\ E-mail: lavruscha@gmail.com
}

\begin{abstract}
Conceptualization of emotions, especially those which are neither universal nor elementary, is a contested area of cognitive linguistic research. The present paper investigated the semantic and conceptual structure of four emotion states of the thematic field 'romantic relationship': love, lust, infatuation, and passion. The specific questions asked in the paper are as follows. First, what are the similarities and dissimilarities between these emotion states? Second, in what way does the conceptualization presented in dictionaries depart from conceptualization that emerges through corpus investigation? Finally, which of the conceptual metaphors posited for emotion concepts by G. Lakoff and M. Johnson are most entrenched in the collective and individual consciousness of speakers of English? To answer these questions, the advantages of four methods were tapped into: introspection, definitional analysis, a native speaker survey and corpus study. Findings reveal that dictionary definitions of love, lust, infatuation, and passion offer an impoverished, if credible, insight into the conceptual structure of these emotions. Results are suggestive of some specific conceptual elements which should be taken account of in a classroom setting by language instructors and L2 learners and indicate which appropriate collocations are to be taken heed of by dictionary compilers.
\end{abstract}

Keywords: emotions, conceptual metaphor, semantic structure, corpus research

Emotions are complex human experiences that have aroused much interdisciplinary interest and debate, so much so that towards the end of the $20^{\text {th }}$ century the term 'emotionology' emerged as referring to a set of beliefs, scenarios and cognitive models for understanding and expressing emotions. As Blount put it back in 1984, 'the past decade has witnessed ... an efflorescence of interest in emotions' (Blount, 1984, p. 130). At the beginning of the new millennium, a flurry of scientific interest in feelings and emotions is gathering momentum, which is evidenced in recent publications on the subject of various emotion states (see below). This interest can be explained by the fact that 'the modern European concept of love is particularly important and that the emergence of this concept in Western folk philosophy constitutes a significant stage in the development of human ideas and human values' (Wierzbicka, 1992, p. 146). While much has been written on the putatively fundamental and universal emotion states - such as interest, joy, surprise, sadness, anger, disgust, contempt, fear (Ekman, 1980; Ungerer \& Schmid, 2006; Lakoff \& Johnson, 2003; Kövesces, 2006, etc.) as well as on love due to its cognitive salience and emotional significance to individuals world over, what has been off the radar of scientific research is a comparative analysis of love and some other - neither universal nor basic emotion states - such as passion, infatuation, lust. While passion and infatuation have been touched upon at least tangentially (Kövesces, 2006; Vukoja, 2014), lust has, to all intents and purposes, been neglected, because the issue has frequently been considered sensitive and unworthy of becoming the subject matter of serious investigation.

The following font conventions are used throughout the paper: italics are employed whenever the conceptual content of emotion states per se is the subject of investigation; single quotes are used 
Table 1

Metaphorical conceptualization of love and linguistic attestations

\begin{tabular}{ll}
\hline love is a journey & $\begin{array}{l}\text { Look how far we've come. We are at a crossroads. It's been a long, } \\
\text { bumpy road. }\end{array}$ \\
\hline love is a physical force & $\begin{array}{l}\text { I could feel the electricity between us. They gravitated to each } \\
\text { other immediately. They lost their momentum. }\end{array}$ \\
\hline love is a patient & $\begin{array}{l}\text { They have a strong, healthy marriage. Their marriage is on the } \\
\text { mend. It's a tired affair. }\end{array}$ \\
\hline love is magic & \begin{tabular}{l} 
She cast her spell over me. The magic is gone. I'm charmed by her. \\
\hline love is war
\end{tabular} \\
$\begin{array}{ll}\text { She fought for him, but his mistress won out. He is slowly gaining } \\
\text { ground with her. She is besieged by suitors. }\end{array}$ \\
\hline love is a container & $\begin{array}{l}\text { He has fallen in/out of love. Your love is empty. } \\
\text { love is a disease (madness) }\end{array}$ \\
\hline
\end{tabular}

when referring to the words that give access to this conceptual content; the unmarked usage indicates that emotion states themselves are the focus of analysis. The terms 'emotion', 'emotion state' and 'feeling' are used interchangeably, as it is outside the purview of the present paper to differentiate between these terms.

\section{Materials and Methods}

\section{Literature Review}

In his 1971 monograph Love and hate: on the natural history of basic behaviour patterns, EiblEibesfeldt defines love as a general, emotional and personal bond between two or more people or 'the bond arising from identification with a particular group' (Eibl-Eibesfeldt, 1971, p. 6). One of the first fundamental cross-cultural investigations of various emotions and feelings was undertaken by Wierzbicka (1992). Although approximately two-thirds of the author's seminal work is devoted to emotions across cultures, passion, lust and infatuation are bypassed, while love is given a rather modest, though accurate and revealing treatment. According to Wierzbicka, who uses universal meta-language in explicating the semantic and conceptual structure of love, it can be glossed as follows:

$X$ is thinking of person $Y$

$X$ feels something good toward $Y$

$X$ wants to do something good for $Y$

What immediately catches the eye is that in Wierzbicka's explication love is considered through the lens of what people feel, think, and how they behave. That is, the author does not make any direct or indirect claims as regards the conceptual structure of love simpliciter. This seems only natural, given the ethnopsychological and anthropological slant of Wierzbicka's monograph.

The primary aim of Wierzbicka's analysis is to compare the concept of English love with its putative equivalents in other languages, such as Ifaluk, Hawaiian, Tahitian and Samoan. The conclusion the author comes to is that, first, the concepts are only partially contiguous, but not identical and, second, that translating the concept of love into other languages presents greater or lesser difficulties, because something always remains backstage; hence, translation equivalence is, to all intents and purposes, unattainable.

A detailed explication of the conceptual structure of love is attested by Lakoff and Johnson (2003) in Metaphors we live by. By ascribing metaphor the status of a universal cognitive mechanism and by analyzing an extensive body of language data, the authors come up with a list of source domains in terms of which the concept of love (the target concept) is arguably structured. This list includes the following domains: journey, physical force, patient, magic, war, container, disease (madness). Table 1 sums up metaphorical conceptualization of love and explicates linguistic attestations (examples) that are reflective of each conceptualization. All the conceptual metaphors for love as well as the examples thereof are Lakoff and Johnson's.

What seems odd and detracts from the credibility of the authors' claims is that in the majority of the attested examples the word 'love' rarely surfaces, which casts a shadow of doubt onto whether it is, in fact, the concept of love that is being explicated, and not some other concept, such as passion, infatuation or even lust. Many of the examples supplied for the love is a patient metaphor explicitly mention the 
concept of marriage. The majority of the examples posited for the conceptual metaphors love is war and love is a disease can theoretically be explications of passion and infatuation. To get round this problem, while drawing examples from the corpus, only those stretches of discourse were analyzed that explicitly mention the concepts under investigation. Another problematic aspect with Lakoff and Johnson's analysis is that no sources of their sample or sample frame are mentioned: one can only speculate whether the examples were invented by the authors themselves relying on their linguistic intuition, whether any corpora or other sources of data were tapped into.

Ungerer and Schmid (2006) suggest analyzing emotion concepts such as anger, fear, passion and lust as scenarios. According to the authors, in comparison with the rest of the emotions (lust, passion and infatuation), love surpasses them all in terms of the sheer number of conceptual metaphors, two of the most salient of which are love is a nutrient and love is magic. Since many of the conceptual metaphors posited for love are shared with the concept of joy, it could tentatively be suggested that the notion of joy could be regarded as a semantico-cognitive component of love, although Ungerer and Schmid do not explicitly make this claim.

A number of other works have investigated different emotion states (e.g., Apresjan, 1997; Bamberg, 1997; Panasenko, 2012; Vukoja, 2014; Baider \& Cislau, 2014). However, no work has been undertaken as regards a comparative analysis of the concepts love, lust, infatuation, and passion using an integrative approach and the advantages of the proposed methods. It is hoped that the findings of the research may not only add to the semantic and cognitive data amassed about the chosen emotion states, but that they might also help individuals to more clearly differentiate between these emotions and to decide which of the emotion states they prefer to be guided by.

\section{Methodology and Data Collection Tools}

All in all, the study comprises four steps, each of which contributes to the understating of the emotion states under investigation. The first step in the analytical procedure was to supply an intuitive insight into the semantics of love, lust, infatuation and passion. This was done using the two different types of introspection - native-speaker and non-native speaker. The non-native-speaker intuition was explored relying on the present author's both intensive and extensive reading on these emotion concepts in the multiple reference sources mentioned at the end of the article as well as in numerous literary texts which either directly or implicitly touch upon these notions. With a view to canvassing native-speaker judgment, a questionnaire was devised in which all the emotion states are presented for analysis using some of the basic ontological criteria suggested by the scholars Whitehead (1917), Russel (1961) and Davidson (2005). These are the following criteria: duration, extension, intensity, spirituality, complexity, mutual compatibility, and intension. According to the above authors, any emotion state can be analyzed applying these criteria. The questionnaire was presented to a female native speaker affiliated with one of the colleges in Oxford, UK. The questionnaire (see Table 2) was sent to her via email with explicit instructions to fill in each of the six sections by putting an $\mathrm{x}$ into a pertinent column with the exception of sections 1 and 6. Section 1 is an open-ended question to which a short phrase or a word is required. Question 6 asks the respondent to connect those states which seem to be compatible; however, the speaker chose to type in a full answer, as this seems to be clearer. Although the total number of intuitive judgments does not seem to be extensive, according to Seliverstova (1988), the specific feature of linguistic intuitive judgment is that it is typically enough to work with one or two respondents with a degree in philology, which compensates for the possible inaccuracy of judgment of an average native speaker who may not be versed in philological matters.

Given that the aim of the present paper is to supply an all-round understanding of the semantic and cognitive structure of love and other emotions orthogonally connected with it, it goes without saying that lexicographical data cannot be bypassed in the procedure. To this end, one of the leading dictionaries on modern English was targeted - The MerriamWebster Dictionary, which contains both linguistic and extralinguistic information. Other dictionaries were also consulted, such as the Macmillan Dictionary of English and the Longman Dictionary of English Language and Culture. However, for lack of space, the present paper explicitly focuses on only one dictionary, given that the data from other dictionaries are convergent. Apart from that, the Merriam-Webster dictionary is based on an extensive corpus of naturally occurring data with a slight bias towards spoken speech. This lexicographical bias can be regarded as a blessing rather than a curse, since spoken language is a better reflection of subconscious, default and therefore most natural conceptualization of phenomena.

The final stage in the methodological procedure was the corpus research, for which the British National Corpus was selected. The advantages of corpus research cannot be overestimated, as 'corpus counts are objective and quantifiable, and computers are well suited to fast and accurate counting' (Schmitt, 2010, p. 67). In selecting the examples, the statistical method of systematic sampling was made use of - every tenth example was selected for the final sample. This ensures the credibility and objectivity of the final sample. To make the data 
valid, the words love and lust were manually annotated for their lexico-grammatical category so that only nouns got selected for the final sample, since the other two emotion states are expressed by words belonging to the 'noun' category. The words love and lust have been annotated manually for the following two reasons: first, theoretically, only the nouns love and lust can be confused with their homophonic verbs and adjectives by virtue of coinciding in form. Second, it has been proved that automatic annotation does not always effectively differentiate between the various meanings of one and the same word, as a result of which confusion arises: thus, 'love' in the meaning of 'no points in tennis' does not have a bearing on the discussed emotion states, and yet it is given back by the BNC in response to the lemma love in the meaning of 'romantic relationship', possibly, because context does not make it 100 percent clear that it is tennis that is being discoursed about.

Both the questionnaire and the corpus analysis count as the experimental part of the research, which serve to check and either validate or disprove the more introspective part of the research comprised by the respondents' analysis and the definitional method.

The main research question is what specific source domains are conceptually borrowed by speakers of English in order to make sense of the more abstract target domains dealing with the chosen emotion states. The hypothesis of the research was that although the common denominator of love, lust, infatuation, and passion is that they are all conceptualized as containers, their 'behaviour' within a container is different, which is crucial to explicate in order to paint a more accurate picture of their conceptual nature.

The results of the analysis are statistically processed and finally presented in the table and graph format, which contain the following data: the most salient attributes in terms of which the emotion states tend to be conceptualized (Tables 3 to 6), the more concrete source domains subconsciously relied on by native speakers in order to make sense of the more abstract and intangible target domains (Fig. 1), the degree of entrenchment of each emotion (Fig. 2), and the container-like visualization of each emotion based on the obtained data (Fig. 3).

\section{Results and Discussion}

\section{Introspective Data}

The following questionnaire was given to the native speaker to complete.

The native-speaker intuition substantiated the nonnative speaker insights. According to the informant, love is the most enduring state, with passion and lust following closely: lust, however, can be a momentary affair, unlike passion, which endures for at least a couple of days. Because passion is a facile feeling, its duration does not extend beyond the limit of a few months. In terms of intensity, two extremes can clearly be distinguished - with lust and passion tilting to the very intense end of the scale, and love and infatuation spanning the 5-to-10 scalar intensity. However, all the states can overlap in their intensity, which is manifest in the shared intensity space running from 8 to 10 . In terms of complexity, love is the most complex feeling, with lust and passion being the simplest, and infatuation spanning the 3-to-5 scalar points. Passion and infatuation, however, overlap in point 3 on the scale, which means that they are both rather superficial feelings.

In terms of spirituality, love and lust share the mind and body parameters, with love affecting one more entity - spirit, which is in sync with love's complex and immaterial nature. As regards the words' extension, the informant believes that all the states can affect people; love and lust can also extend to animals. This extension, however, should be construed differently in each case: whereas love - when it affects animals - makes them more human-like and humane, as it were, lust - when it grips a human being - makes them more animal-like.

The mutual compatibility parameter has revealed that all the four states are inter-compatible - something that was not immediately apparent from the rest of the sources, which elicited converging evidence that lust is in stark contrast to the other states.

\section{Definitional Analysis}

Conflating and juxtaposing data on love, lust, infatuation, and passion from the Merriam-Webster Dictionary, the following findings have been obtained.

Of all the meanings of love, the most relevant for the present analysis are the meaning of strong affection for another arising out of kinship or personal ties; attraction based on sexual desire; affection based on admiration, benevolence, or common interests; warm attachment, enthusiasm and unselfish loyal and benevolent concern for the good of another. The list of synonyms provided at the end of the dictionary entry reveals that passion is the pseudo-synonym of love, which is quite far removed from it, though. The etymology of the word love (Latin lubere, libere 'to please') shows that at the present stage of its semantic structure the meanings of its lexico-semantic variants are compatible with the semantic motivation of love and with the intuitive analysis provided at the beginning of the article.

For passion, of relevance are lexico-semantic variants that encompass the meaning of suffering; the state or capacity of being acted on by external agents or forces; an intense, driving, overmastering feeling or conviction; ardent affection; a strong liking or desire 
Table 2

Native-speaker contribution to the semantico-cognitive analysis of the emotion states love, lust, infatuation, passion

\section{Duration}

For approximately how long can the state potentially last?

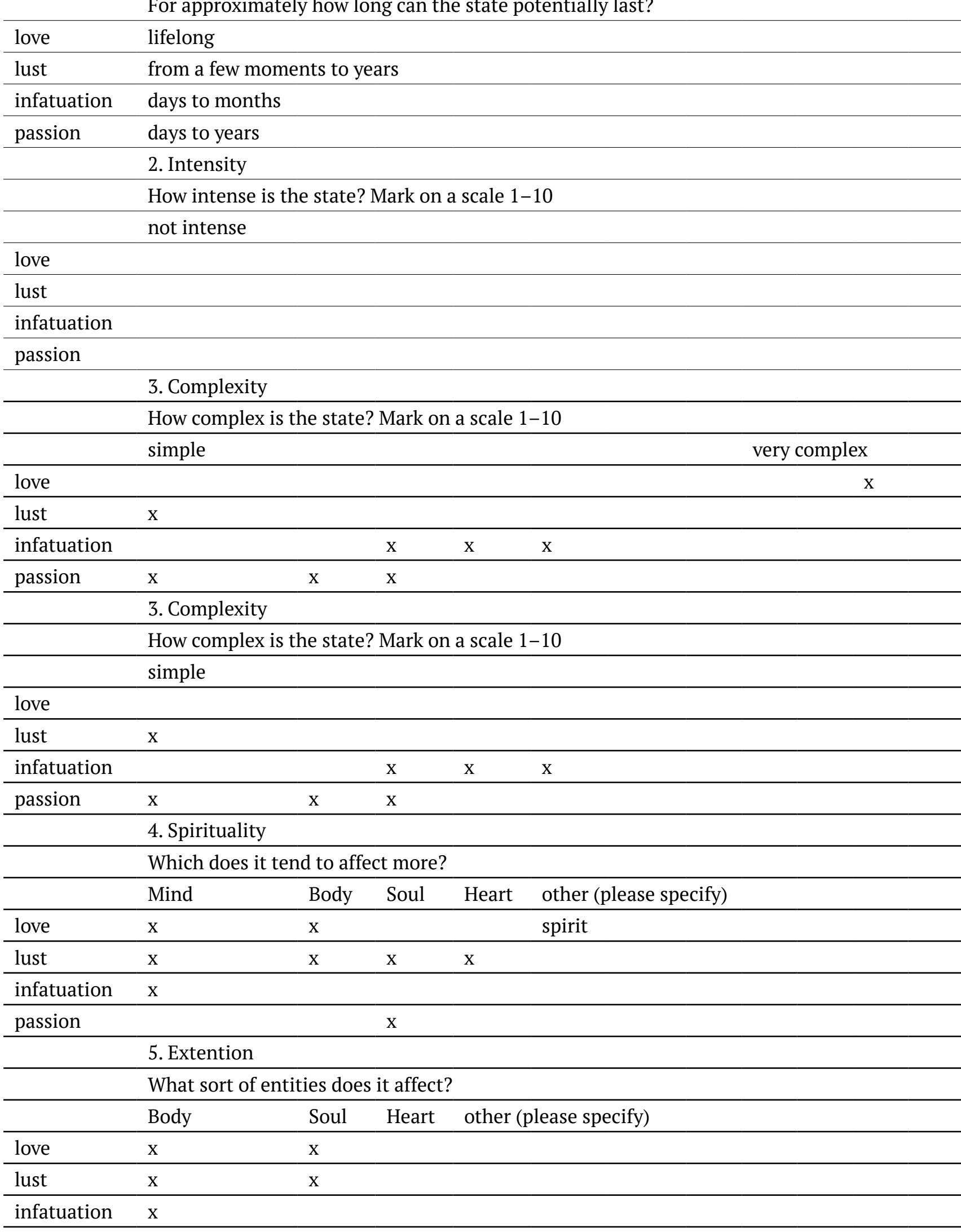


for or devotion to some activity, object, or concept. Of relevance are also three semantic features: suffering, external agents or forces and the ontological category of emotions it belongs to. The suffering component reveals that passion is not wholesome to individuals who are possessed by it: it creates spiritual or physical turmoil. This seems to be consonant with the nonnative speaker intuition spelt out above. The fact that it is caused by external forces shows that an individual is not responsible for both the presence of passion and its repercussions: unlike love, passion is hard to control and it is unlikely to be volitionally cultivated by an individual, which is possible in the case of love.

All the meanings of lust and all the lexico-semantic variants seem to be of relevance. The quotation from W. Shakespeare - 'love comforteth, like sunshine after rain, but lust's effect is tempest after sun' - suggests that lust is opposed to love, although they are not treated by the dictionary as incompatible: in the synonyms section the word 'lustfulness' is given as 'love"s synonym. The sentential illustration 'He was motivated more by lust than love' indicates that 'love' and 'lust' may be thought of as synonym-like entities. This is because antonyms do not felicitously occur with the comparative structure 'more by...than', they fit more appropriately in the structure 'by..., not (by)...', as, for example, in the sentence He was motivated by greed, not (by) charity. Being close to passion, lust is defined as unbridled carnal desire. The key feature that supposedly holds together all the meanings is pleasure that is hard to resist. Like passion, lust is construed as coming from without, as an overwhelming force that threatens to subjugate, enslave and, possibly, do harm to its victim.

For infatuation, the meaning of strong and unreasoning attachment, especially to something unworthy of attachment, is particularly revealing. A suggestive semantic feature that was not mentioned in the intuitive understanding of this emotion is that it is directed at or caused by something unworthy of attachment. This feature is a direct consequence of the unreasoning behaviour that obtains when one is infatuated with somebody or something.

The comparative and contrastive analysis of the chosen emotion states has revealed that, on the whole, the intuitive (both non-native speaker and native speaker) understanding of the semantic and cognitive structure of love, lust, passion, infatuation is compatible with their dictionary treatment, although there are some components provided by the dictionary that were not part of the original understanding of some of the emotion states: in the case of passion it was not at all apparent that suffering is somehow integral to it; lust was not immediately linked with enthusiasm or ambition; infatuation did not seem to be characterized by lack of reason or primarily directed at objects not worthy of attachment.

\section{Corpus Data}

The corpus study has revealed that traditional dictionary definitions are impoverished in terms of some of the semantic and conceptual elements that are in fact associated with each state accessed through pertinent words. Below are the criterial grids (Tables 3 , $4,5,6)$ which reflect in summary the results of the corpus research of the semantico-cognitive structure of love, lust, passion, infatuation. In the tables, the expressions in bold are indicative of some of the semantico-cognitive attributes which were not apparent from all the other types of analysis. The expressions in brackets are some of the recurrent phrases from the BNC. The corpus research is suggestive of some of the most frequent and entrenched collocations, which are typically given short shrift by dictionaries. Apparently, this is not a deliberate policy on the part of dictionary editors: lack of space, time, the awkwardness of updating a version of a dictionary on a regular basis and the sheer impossibility to keep track of the shifting conceptual parameters predispose dictionary compilers to opt for the safest choices, which, although being quite frequent and indispensable for L2 learners, may sound clichéd, overused and fail to indicate how the studied emotions are conceived of in reality - by native speakers of English. For 'love', most dictionaries highlight such expressions as 'true love', 'to fall in love', 'unrequited/ unconditional love', 'love at first sight'. Ironically, these expressions are not top of the list according to the corpus data, which strongly suggest that 'a sign of love', 'words of love', 'to declare one's love for smb.', 'the love of a human heart', 'everlasting love' are much more frequent and entrenched. For 'infatuation', these are such expressions as 'girlish/teenage infatuation', 'youthful infatuation', 'infatuation of old men', 'infantile infatuation', 'in the grip of infatuation', 'passing infatuation', 'blind infatuation', 'there is a great chasm between love and infatuation'. The word 'lust' attracts such attributes as 'casual', 'male', 'undying', and 'sinful', while the collocates 'unbridled', 'guilty', 'illicit', 'crime', 'overpowered', and 'frenzied' cluster around the word 'passion'.

Another contribution of the corpus research is that it clarifies the types of the evaluative connotation the emotions tend to have, and that it might be in flux: while the connotation for lust is clearly negative, this does not always hold true for infatuation and passion, both of which occasionally reveal a positive connotation. The corpus analysis also revealed that all the concepts share the meaning of "enthusiasm for smth.”. The exclusive contribution of corpus research is the way the relevant notions tend to be conceptualized: passion and lust are construed as "heat" (or "hot"); lust and infatuation are conceptualized as a kind of disease; passion and lust also construed as "crime" and love - as "a container" 
Table 3

Criterial grid of semantic and conceptual structure of love

\begin{tabular}{|c|c|}
\hline Emotion state & love \\
\hline $\begin{array}{l}\text { Attributes (elements of } \\
\text { semantic and conceptual } \\
\text { structure) }\end{array}$ & $\begin{array}{l}\text { integral part of life (love life - 20\%), requires capacity (a capacity for } \\
\text { love - } 15 \% \text { ), deep (depth of love - 15\%), long-lasting (everlasting love - } \\
8 \% \text { ), compatible with passion (the passion of love - } 5 \% \text { ), needs to be } \\
\text { verbalized (to declare one's love for smb. - } 9 \% \text {, a love song }-6 \% \text {, love } \\
\text { letters }-6 \% \text {, words of love }-4 \% \text {, a poem of love }-3 \% \text {,), has telltale } \\
\text { symptoms (a sign of love }-7 \% \text { ), resides in the heart (the love of a } \\
\text { human heart - } 2 \% \text { ) }\end{array}$ \\
\hline Lexico-semantic variants & $\begin{array}{l}\text { 1) Enthusiasm, desire, emotional attachment (love of truth/music/art) } \\
\text { 2) Strong feeling of attraction for smb. or smth. (to fall in love with } \\
\text { smb., to love the bacon/the radio) } \\
\text { 3) Sexual act (to make love) }\end{array}$ \\
\hline Strongest collocational links & $\begin{array}{l}\text { love life, to fall in love, love of smth., my love (a form of address), } \\
\text { to make love }\end{array}$ \\
\hline Overall evaluative connotation & expressly positive \\
\hline Conceptualized as & $\begin{array}{l}\text { container, physical entity (the depth of love, to fall in love, } \\
\text { to give/show/smell love) }\end{array}$ \\
\hline
\end{tabular}

Table 4

Criterial grid of semantic and conceptual structure of love

\begin{tabular}{ll}
\hline Emotion state & lust \\
\hline $\begin{array}{l}\text { Attributes (elements of } \\
\text { semantic and conceptual } \\
\text { structure) }\end{array}$ & $\begin{array}{l}\text { not serious (casual lust - 12\%), mostly male (male lust - 10\%), } \\
\text { strongly opposed to love (war between love and lust - 9\%), might } \\
\text { be persistent (undying lust - 7\%), hard to control (to restrain one's } \\
\text { lust - 6\%), bodily emanation (carny lust - 4\%), one loses reason and } \\
\text { vision (obsessive lust - 8\%, to be wild with lust - 4\%, blinded by lust - } \\
4 \% \text { ), negative scenario, consequences (can end up in adultery - 9\%, } \\
\text { extramarital sex or unsought pregnancies - 13\%) sinful, bad agent } \\
\text { (the sin was lust - 8\%, victim of the lust - 6\%) }\end{array}$ \\
\hline Lexico-semantic variants & $\begin{array}{l}\text { 1) Enthusiasm (lust for novelty/power/a tan/life) } \\
\text { 2) Strong carnal desire (mere lust and desire, an excitation of lust, } \\
\text { lascivious lust) }\end{array}$ \\
\hline Strongest collocational links & lust for smth., lust for life, blood lust, love or lust \\
\hline Overall evaluative connotation & expressly negative \\
\hline Conceptualized as & crime, disease, heat \\
\hline
\end{tabular}

and "a physical entity". The percentile rank for each emotion has been rounded.

On the Euler diagram below (Figure 1) are plotted the source domains in terms of which each state is conceptualized according to the data obtained from the corpus.

Out of the 22,348 hits given back by the BNC in response to the entry 'love', approximately one third is constituted by nouns, although there are problematic cases to account for given that, due to the typology of the
English language, nouns are not clearly differentiated from adjectives. In such cases, only unequivocal hits were taken into account. Out of the meager 460 hits returned for 'lust', a good 86 percent are constituted by nouns. There is a diachronic explanation for this result, which is that the verb 'to lust' was derived by the process of conversion, unlike in the case of the pair 'love' - 'to love', which existed side by side in Old English in the forms 'lufu' and 'lufian', respectively, and converged in the process of historical development of their phonetic 
Table 5

Criterial grid of semantic and conceptual structure of infatuation

\begin{tabular}{|c|c|}
\hline Emotion state & infatuation \\
\hline $\begin{array}{l}\text { Attributes (elements of } \\
\text { semantic and conceptual } \\
\text { structure) }\end{array}$ & $\begin{array}{l}\text { one might lose one's mind and vision (blind infatuation }-13 \% \text { ), facile } \\
\text { (it is just infatuation }-11 \% \text {, ridiculous infatuation }-11 \% \text { ), leads } \\
\text { nowhere (to be led astray by infatuation }-7 \% \text {, nothing would ever } \\
\text { come of it }-6 \% \text { ), affects the young and the old (girlish infatuation - } \\
8 \% \text {, infantile infatuation }-8 \% \text {, youthful infatuation }-7 \% \text {, infatuation } \\
\text { of old men - } 6 \% \text {, teenage-flavoured infatuation - } 2 \% \text { ), intense, but } \\
\text { quick to disappear (passing infatuation }-11 \% \text {, will wear off - } 4 \% \text {, in } \\
\text { the grip of infatuation - } 4 \% \text { ), wrong, opposed to love (there is a great } \\
\text { chasmbetween love and infatuation }-2 \% \text { ) }\end{array}$ \\
\hline Lexico-semantic variants & $\begin{array}{l}\text { 1) Enthusiasm (infatuation with multiculturalism/hightech/rap/for the } \\
\text { well-proportioned figure) } \\
\text { 2) Intense, but misplaced feeling of attraction for smn. or smth. } \\
\text { (infatuation with Joan/him/her) }\end{array}$ \\
\hline Strongest collocational links & passing infatuation \\
\hline $\begin{array}{l}\text { Overall evaluative } \\
\text { connotation }\end{array}$ & mostly negative \\
\hline Conceptualized as & $\begin{array}{l}\text { disease (to recover from infatuation, it is a sort of brain disease, } \\
\text { unhealthy infatuation) }\end{array}$ \\
\hline
\end{tabular}

Table 6

Criterial grid of semantic and conceptual structure of passion

\begin{tabular}{ll}
\hline Emotion state & passion \\
\hline $\begin{array}{l}\text { Attributes (elements } \\
\text { of semantic and conceptual }\end{array}$ & $\begin{array}{l}\text { difficult to control (unbridled passion - 15\%), against the law or } \\
\text { immoral, may lead to a crime (illicit/ guilty passion - 14\%, crime of } \\
\text { structure) }\end{array}$ \\
$\begin{array}{l}\text { passion - 32\%), strong, powerful (to be overpowered by passion - } 9 \%), \\
\text { short-lived (the passion of a moment - 14\%), compatible with love } \\
\text { (to love with a passion - 12\%), part of human fallen nature (human } \\
\text { passion instead of divine reason - 4\%) }\end{array}$ \\
\hline
\end{tabular}

Lexico-semantic variants $\quad$ 1) Enthusiasm (passion to fly/to travel/for acting/ football/the truth

2) Carnal desire or sexual act (passion for a girl/for her, unbridled passion, to master one's passion, squeals of passion, sexual passion, the passion of sexual intercourse) 3) Strong emotional state (fits of passion, burst of passion, frenzied passion, to love with an ardent passion)

\begin{tabular}{ll}
\hline Strongest collocational links & crime of passion, real passion, to share a passion, a passion for smth \\
\hline Overall evaluative connotation & negative \\
\hline Conceptualized as & $\begin{array}{l}\text { heat (the heat of passion, the fire of passion, burning passion) } \\
\text { crime (illicit, guilty passion, crime of passion) }\end{array}$ \\
\hline
\end{tabular}

shape. The divergence between the sheer number of hits as regards love and lust indicates that love is a more salient and entrenched concept out of the two. In response to 'passion', the BNC returns 2,206 hits per one million words, all of which, as expected, are nouns, since conversion does not effectually operate on this lexeme. Only a hundred entries are found in response to 'infatuation', which never occurs as a verb, given that the noun form is regularly and productively derived from the verb 'to infatuate'. All told, the concept of 'love' seems to be a permanent presence in the collective consciousness of native speakers, followed by passion, lust and infatuation, of which the last state is the least entrenched. The comparative degree of entrenchment 


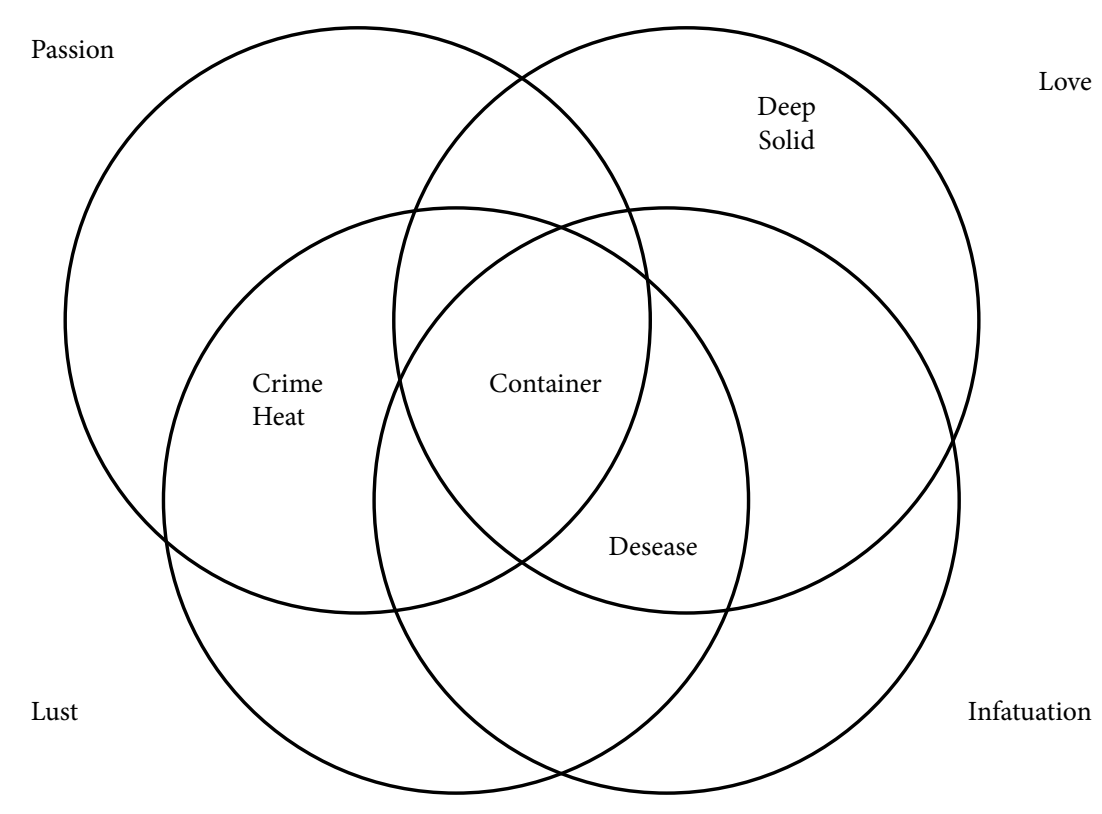

Figure 1. The source domains in terms of which love, lust, infatuation, and passion are conceptualized (on the basis of the data obtained from the BNC).

of the four emotion states is plotted on the bar chart below.

Since according to the cognitive tenet of embodied cognition all emotions are conceptualized as containers, it is possible to metaphorically place love, lust, infatuation and passion into a container and see what happens both to the emotions and to the container itself. This

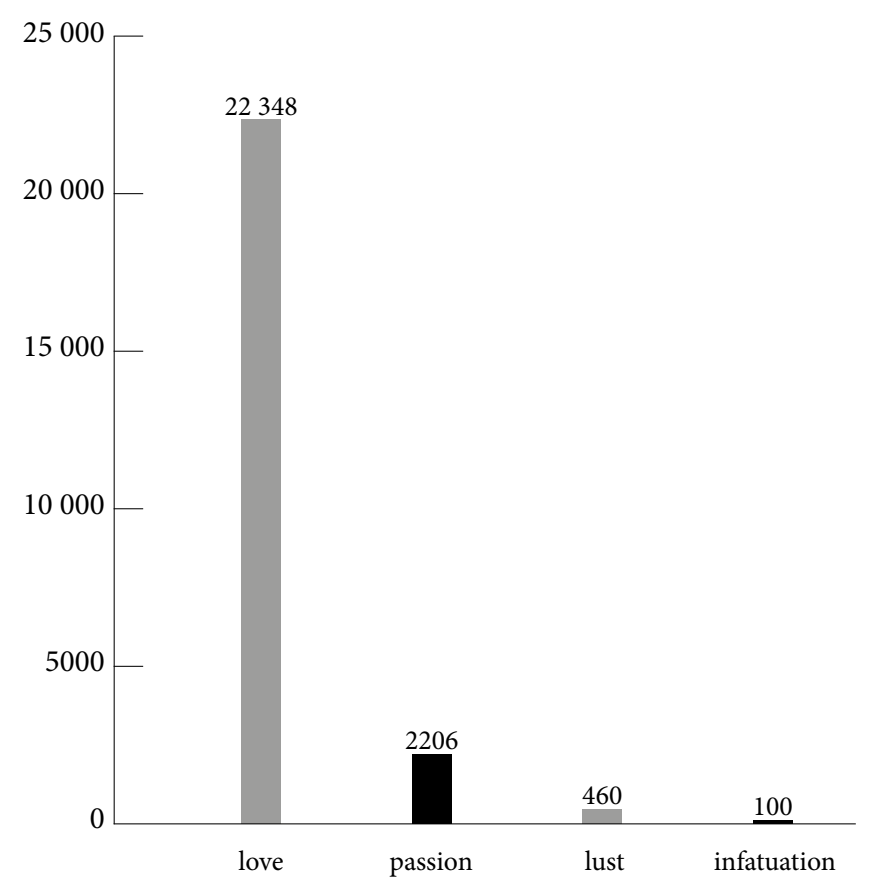

Figure 2. The degree of entrenchment of love, lust, infatuation, and passion. procedure is licensed by the so-called 'implications' of conceptual metaphors: the important consequence of any conceptual metaphor is that knowledge about the source-domain can be extrapolated to the targetdomain, because some properties and characteristics of the former are inherited (borrowed) by the latter. Unlike lust and passion, love and infatuation are paired and contrasted in terms of the conceptual element depth: infatuation has turned out to be shallow, while love is posited to be deep. Lust and passion are paired in terms of the heat and hence pressure component: it is known from physics that when temperature increases within a confined space, pressure builds up. The marked difference between depth and intensity is that depth is directed down, while intensity can spread in all the four possible directions - upward, downward, left and right. Containers are usually enclosed from at least three sides, with the fourth - the lid - being optional, though usually necessary to keep whatever within the container in safety. However deep a container is, it has the bottom, and so love, when it figuratively reaches the bottom, stays there. Since intensity is characterized by a high and potentially mounting degree and since it is likely to spread in all the available directions, if there is no lid on the container, intensity (metonymically standing for lust and passion) will go over the top; if there is one, it will blow the lid off, or if the lid is too tight, the container is likely to burst.

The 'behaviour' of infatuation confined within the container is more difficult to pinpoint, partly because of the diverging evidence retrieved from the corpus and the native-speaker analysis. According to the native 
speaker informant, infatuation is conceptually closer to love because it is characterized by the same potential intensity and is more complex than lust and passion. The corpus research, however, revealed that infatuation is a rather shallow state not likely to last for a very long time. Conflating all the evidence, it seems that infatuation is a rather harmless state and in this it partly resembles love. Unlike love, however, infatuation is volatile rather than resting at the bottom of the container (as love would as it is solid and stable), it is likely to travel its entire inside, without, however, exerting much pressure on any of the four sides. Note that the word volatile is used without the negative overtones and simply suggests the property of moving about as if by flight (see the definition in the Merriam-Webster Dictionary). Figure 3 illustrates conceptualization and 'behaviour' of love, lust, infatuation, and passion.

\section{Summing Up}

Overall, the results of the research into the semantico-cognitive structure of the emotion concepts love, lust, infatuation, passion can be summarized as follows.

First, although the concept of love turned out to be the most contested one out of the four - as it seems to combine depth, stability, intensity, heat and pressure, overall, positive connotations, and, therefore, depth and stability, prevail over the more pronounced negative connotations of lust, passion and infatuation, for which instability, pressure, heat and intensity are conceptually salient, while depth and stability do not surface at all. Second, it has been revealed that these emotion concepts are primarily dynamic entities, although love seems to be the most stable of all. Third, the corpus research has highlighted some of the associations with the chosen emotions. These associations are not necessarily registered by dictionaries, though they are part of native speakers' conceptualization. Thus, it is not reflected by the Merriam-Webster dictionary (or, indeed, other English dictionaries, such as the Macmillan Dictionary of English and the Longman Dictionary of English Language and Culture) that lust is mostly thought of as a male attribute, that it might be persistent, that the consequences of indulging one's lust are likely to be negative. For love, it may not have been immediately apparent that it resides in the heart (rather than the mind or the soul), that it is so strong a feeling that it has telltale signs and needs to be verbalized or that it can be directed at oneself, unlike lust, passion or infatuation. Apparently, this information should be taken into account by dictionary compliers, as it enriches the purely linguistic meaning of each word. Fourth, the research has been indicative of the most typical and, therefore, strongest collocations for each emotion word, which is of practical, educational and

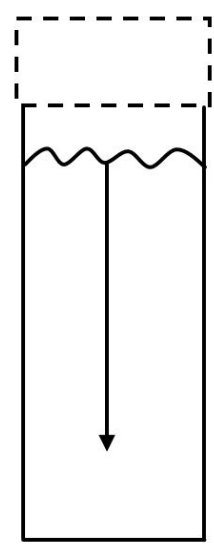

love

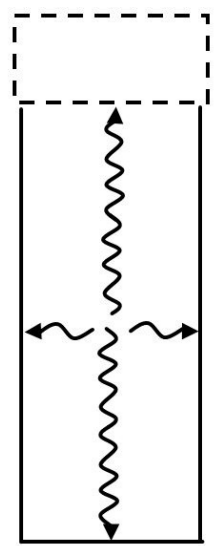

lust, passion

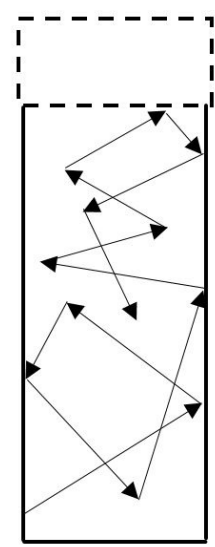

infatuation
Figure 3. The 'container' conceptualization of love, lust, infatuation, and passion.

methodological value, as it helps both L1 and L2 learners and language instructors: learners will know how to correctly apply the relevant emotion word in context; instructors will know which expressions should be taught first, as they are more typical. Fifth, out of the conceptual source domains posited for love by Lakoff and Johnson (1980), the ones that seem to be most salient for native speakers are 'container' and 'disease', although 'container' seems to take the upper hand. One source domain that is not explicitly mentioned by Lakoff and Johnson is that of a palpable 'physical entity (object)'. What they mention is the 'physical force' (gravitational, electromagnetic), which is different from a particular object. This divergence in findings may be due to the fact that within the framework of the present research only those stretches of discourse were analyzed that contain the word 'love'. As is mentioned at the beginning of the article, this was done with a view to enhancing the validity and credibility of the findings: the only safest way to ensure that it is the target emotion concept that is being investigated is to select only those stretches of discourse which mention the target concept explicitly. The 'warmth' and the 'heat' conceptual components posited for love by Wierzbicka (1992) in Semantics, culture and cognition and Kövecses (2006) in Language, mind and culture respectively, proved to be rather marginal, although the 'heat' component is quite pronounced for lust. The 'disease' component is shared by three emotion states - love, lust and infatuation, and seems to be marginal to passion, for which the 'heat' and the 'crime' conceptual elements are most entrenched.

\section{Conclusion}

Research results have far-reaching pedagogical implications in that specific collocations with the names 
of these emotion states should be primarily taught at intermediate and advanced stages of language learning and instruction rather than presented in isolation. This contextually-bound approach will make for a deeper conceptualization of these emotions and will help L2 learners to grasp the notions that stand behind them.

The findings of the research are provisional and could be enhanced and fine-tuned by further investigation of the semantic and cognitive structure of love, lust, passion and infatuation in the following ways. First, it would be of interest to see whether the concept of love is a unitary one, which is complex and contradictory, or whether it is more accurate to posit a 'fission' of the originally single concept into two or, possibly, more, just like Ungerer and Schmid (2006) predicted. A bi-polar nature of love calls for a separate investigation. Second, the method of literary authority could be tapped into by analyzing with its help in what way the concepts of love, lust, infatuation, and passion have been changing over the years, what entrenched conceptual metaphors - both generic and specific-level ones - are most salient for different authors, and what innovative metaphors are created by writers working within various literary canons. Third, the paper could be significantly extended and nuanced by amassing a larger sample through enlisting the help of more native speakers of English, by comparing the gender and age differences in conceptualizing different emotion states and by looking into the ways in which the nearly default and semi-automatic conceptualization differs from deep, discursive, philosophical essays on love and other emotion states. Finally, the questionnaire presented to prospective respondents could be enhanced considering the data obtained from the BNC by incorporating more parameters in terms of which emotion states can be analyzed, such as the age group each emotion tends to affect and the source domains that seem to be most fitting for the conceptualization of each emotion.

\section{References}

American Bible Society. (1976). Good news Bible. Retrieved from https://www.bible.com/ru/ versions/68-gnt-good-news-translation

Apresjan, V. (1997). Emotion metaphors and crosslinguistic conceptualization of emotions. Cuadernos de Filologia Inglesa, 612, 179-195.

Bamberg, M. (1997). Language, concepts, and emotions: The role of language in the construction of emotions. Language Sciences, 19(4), 309-340.
Blount, B. (1984). The language of emotions: An ontogenetic perspective. Language Sciences, 6(1), 129-156.

Eibl-Eibesfeldt, I. (1971). Love and hate: On the natural history of the basic behaviour patterns. London, UK: Methuen.

Ekman, P. (1992). Facial expressions of emotion: New findings, new questions. Psychological Science, 3, 34-38.

Gallie, G. B. (1956). Essentially contested concepts. Proceedings of the Aristotelian Society, 51, 167-198.

Gove, P. B. (Ed.). (2013). Webster's third international dictionary for iOS 3.35 [electronic version]. London, UK: Paragon Software Group.

Kövecses, Z. (2006). Language, mind and culture. Oxford, UK: Oxford University Press.

Lakoff, G., \& Johnson, M. (2003). Metaphors we live by. Chicago, IL: University of Chicago Press.

Langacker, R. W. (2008). Cognitive grammar: A basic introduction. Oxford, UK: Oxford University.

Lutz, C. (1982). The domain of emotion words on Ifaluk. American Ethnologist, 9(1), 113-128.

Panasenko, N. (2012). Linguistic markers of emotional concept "love" in literary texts. US-China Foreign Language, 10(4), 1067-1084.

Schmitt, N. (2010). Researching vocabulary. A vocabulary research manual. London, UK: Palgrave Macmillan.

Seliverstova, O., \& Suleimanova, O. (1988). Experiment in semantics. News of Academy of Sciences. Series Literature and Language, LXVI(5), 431-445.

Tissari, H. (2003). Lovescapes: Changes in prototypical metaphors and cognitive sense since 1500. Helsinki, Finland: Société Néophilologique.

Tissari, H. (2010). English words for emotions and their metaphors. In M. E. Winters, H. Tissari \& K. Allan (Eds.), Historical cognitive linguistics (pp. 298-329). Berlin, Germany: Mouton de Gruyter.

Trim, R. (2010). Conceptual networking theory in metaphor evolution: Diachronic variations in models of love. In M. E. Winters, H. Tissari \& K. Allan (Eds.), Historical cognitive linguistics (pp. 223-260). Berlin, Germany: Mouton de Gruyter.

Ungerer, F., \& Schmid, H.-J. (2006). An introduction to cognitive linguistics. London, UK: Pearson, Longman.

Vukoja, V. (2014). Passion: A forgotten feeling. In F. H. Baider \& G. Cislaru (Eds.), Linguistic approaches to emotion in context (pp. 39-70). Zagreb, Croatia: John Benjamins.

Wierzbicka, A. (1992). Semantics, culture and cognition. Universal human concepts in culture-specific configurations. Oxford, UK: Oxford University Press. 